\title{
Evli Kadınların Aile İçi Şiddete Maruz Kalma Durumu ve Etkileyen Faktörler
}

\author{
Prof. Dr. Havva Tel ${ }^{1}$ \\ Dr. Öğr. Üyesi Semra Kocataş \\ Prof. Dr. Nuran Güler ${ }^{3}$ \\ Prof. Dr. Hatice Tel Aydın ${ }^{4}$ \\ Dr. Öğr. Üyesi Nurcan Akgül Gündoğdu ${ }^{5^{*}}$
}

Geliş tarihi: 27.08.2019

Kabul tarihi: 13.09.2019

\section{Atuf bilgisi:}

IBAD Sosyal Bilimler Dergisi

Sayı: Özel Sayı Sayfa: 256-264

Yıl: 2019

This article was checked by Turnitin. Similarity Index $30 \%$.

${ }^{1}$ Sivas Cumhuriyet Üniversitesi, Türkiye, havvatel@yahoo.com.

ORCID ID 0000-0001-9171-2115

2 Sivas Cumhuriyet Üniversitesi, Türkiye, skocatas@gmail.com

ORCID ID 0000-0001-7566-0060

${ }^{3}$ Sivas Cumhuriyet Üniversitesi, Türkiye, nuranguler@yahoo.com.tr, ORCID ID 0000-0002-3411-6912

${ }^{4}$ Sivas Cumhurivet Üniversitesi, Türkive, haticetel@gmail.com,

ORCID ID 0000-0002-1518-8080

${ }^{5 *}$ Sivas Cumhuriyet Üniversitesi, Türkiye, nr.akgul@gmail.com

ORCID ID 0000-0002-6446-730X

* Sorumlu yazar öz

$\mathrm{Bu}$ çalışma evli kadınların aile içi şiddete maruz kalma durumunu ve etkileyen faktörleri belirlemek amacı ile yapılmıștır. Tanımlayıcı tipte olan araștırmanın evrenini 18 yaş ve üzeri, evli 330 kursiyer kadın, örneklemini ise 220 kadın oluşturmuştur. Araştırma verileri "kişisel bilgi formu" "kadına yönelik aile içi şiddeti belirleme ölçeği" ile toplanmıştır. Verilerin değerlendirilmesinde sayı, yüzdelik dağılım ki-kare testi, t testi ve varyans analizi kullanılmıştır. Araştırmaya katılan kadınların \%69.5'i görücü usulü ile evlendiğini, \%30.5'i eşinden şiddet gördüğünü belirtmiştir. Tanışarak evlenen, fiziksel hastalı̆̆1 veya ruhsal hastalığ1 olan ve eşinden şiddet gördüğünü ifade eden kadınların kadına yönelik ev içi şiddeti belirleme ölçeği puan ortalamasının daha yüksek olduğu saptanmıştır. Bu sonuçlar doğrultusunda; kadınların aile içi es şiddet türleri ve aile içi es şiddetinin tedavi edilmesi gereken bir sorun olduğu konusunda bilgilendirilmesi, şiddet yaşantısında yardım ve destek alacakları kaynaklarının tanıtılması, şiddetin sonuçlarına yönelik farkındalıklarının artırılması önerilmektedir.

Anahtar Kelimeler: Kadın, aile içi şiddet, ilişkili faktörler, hemşirelik 


\title{
Status of Domestic Violence Exposure among Married Women and the Affecting Factors
}

\author{
Prof. Dr. Havva Tel ${ }^{1}$ \\ Assist. Prof. Dr. Semra Kocataș² \\ Prof. Dr. Nuran Güler ${ }^{3}$ \\ Prof. Dr. Hatice Tel Aydın ${ }^{4}$ \\ Assist. Prof. Dr. Nurcan Akgül Gündoğdu ${ }^{5^{*}}$
}

First received: 27.08 .2019

Accepted: 13.09.2019

\section{Citation:}

IBAD Journal of Social Sciences

Issue: Special Issue Pages: 256-264

Year: 2019

This article was checked by Turnitin. Similarity Index 30\%.

${ }^{1}$ Sivas Cumhuriyet University, Turkey, havvatel@yahoo.com.

ORCID ID 0000-0001-9171-2115

2 Sivas Cumhuriyet University, Turkey, skocatas@gmail.com

ORCID ID 0000-0001-7566-0060

${ }^{3}$ Sivas Cumhuriyet University, Turkey nuranguler@yahoo.com.tr, ORCID ID 0000-0002-3411-6912

${ }^{4}$ Sivas Cumhuriyet University, Turkey, haticetel@gmail.com,

ORCID ID 0000-0002-1518-8080

${ }^{5 *}$ Sivas Cumhuriyet University, Turkey, nr.akgul@gmail.com

ORCID ID 0000-0002-6446-730X

* Corresponding Author

\begin{abstract}
This study was conducted with the aim to determine the status of married women exposed to domestic violence and related factors. The population of this descriptive study consisted of 330 trainee women who are 18 years old and over and married, and the sample consisted of 220 women. The research data were collected with "personal information form", "domestic violence against women scale". Number, percentage distribution chi-square test, $t$ test and variance analysis were used in the evaluation of the data. $69.5 \%$ of the women who participated in the study stated that they were married by arranged procedures and 30.5\% stated that they were subjected to violence from their spouses. Women who met and married, who had physical or mental illness and who stated that they had been subjected to violence from their husbands were found to have a higher mean score for determining domestic violence against women.
\end{abstract}

Keywords: Woman, domestic violence, related factors, nursing 


\section{GİRIŞ}

Kadına yönelik aile içi şiddet, kadının birlikte yaşadığı aile üyeleri genellikle eşi tarafından uygulanan, kadını inciten, zarar veren, fiziksel, cinsel, ruhsal hasarla sonuçlanabilen, toplum içerisinde ya da özel yaşamda kadına baskı uygulanmasına ve özgürlüklerinin keyfi olarak kısıtlanmasına neden olan davranışları içermektedir (WHO, 2002; Roman and Frantz, 2013, s.257). Kadına yönelik ev içi şiddet yaş, eğitim, sosyoekonomik düzey farkı olmaksızın tüm kadınların yaşadığı ortak bir sorundur. Fiziksel, psikolojik, ekonomik ve cinsel şiddet şeklinde görülen kadına yönelik ev içi şiddet günümüzde yaygınlığı artan bir salgın olarak değerlendirilmektedir (Stöckl et al., 2013, s.861; Selvi ve Karanfil, 2016, s.62). Birçok araştırma sonucu kadına yönelik ev içi şiddetin dünyada ve ülkemizde sık görülen bir sorun olduğunu ortaya koymaktadır. Yapılan araştırmalarda; dünyada 10 farklı ülkede 2000 ile 2004 yılları arasında yapılan bir araştırmada 15- 49 yaş grubundaki kadınların \% 13 -61'inin eşinden sürekli olarak fiziksel ya da cinsel şiddet gördüğü (WHO, 2005), Amerika'da her dört kadından birisinin eşi veya erkek arkadaşı tarafindan fiziksel ya da cinsel şiddet gördüğü (Miller et al., 201, s.914), bir başka çalışmada ise dünya genelinde kadınların \%35'inin eşi veya partneri tarafindan cinsel veya fiziksel şiddete uğradığı saptanmıştır (WHO, 2013), Türkiye'de yapılan çalışmalarda da her üç kadından birinin kadına yönelik aile içi şiddet yaşadığı (Altınay ve Arat, 2007), sosyoekonomik düzeyi düşük bir bölgede yaşayan 15 yaş ve üzeri kadınların \%88.1'inin fiziksel şiddet gördüğü (Efe ve Ayaz, 2010, s.27), ev içi şiddet yaşayan kadınların \%38'inin fiziksel, \% 12'sinin cinsel ve \% 44'ü duygusal şiddete maruz kaldığ1 (Türkiye'de Kadına Yönelik Aile İçi Şiddet Araştırması, 2015), gebe olan veya gebelik öyküsü olan kadınla yapılan bir çalışmada ise kadınların \% 81.82'inin ilk gebeliğinde şiddete maruz kaldığı belirlenmiştir (Ayranc1 et al., 2002, s.84).

Kadına yönelik aile içi şiddet kadın ve erkekler arasında eşit olmayan güç ilişkileri sonucu ortaya çıkmakta, kadının temel insan hak ve özgürlügünü ihlal etmekte, sıklık ve yaygınlığı artmaktadır (Kaplan et al., 2014, s.27). Kadına yönelik ev içi şiddetin artmasında; şiddeti uygulayan kişinin benlik saygısının düşük olması, aşırı alkol tüketmesi, ekonomik sıkıntı yaşaması, işsizlik, depresyon ya da kişilik bozukluğu tanısı olması, çocukken şiddete maruz kalması ya da şiddete tanık olması, şiddet içerikli film ve diziler izlemesi, yakın çevresinin şiddeti desteklemesi, eşler arasında iletişim yetersizliği, kadının fiziksel güç ve zor kullanmayı hoşgörü ile karşılaması gibi faktörlerin etkili olduğu belirtilmektedir (Demir, 2000, s.59; Tatlılıŏlu ve Küçükköse, 2015, s.196). Ayrıca toplumda şiddetin tüm evliliklerde olduğu düşüncesi, şiddet uygulayan kişinin bir gün düzeleceğine inanma anlayışının olması kadına yönelik ev içi şiddettin süreklilik kazanmasına katkı vermektedir. Kadına yönelik aile içi şiddet yalnızca şiddet gören kadını değil aile üyelerini ve toplumu da etkilemekte, ciddi sağlık sorunları ve ekonomik sonuçlara neden olmaktadır. Kadına yönelik aile içi şiddet sonucu kadının fiziksel ve ruhsal sağlığı bozulmakta, benlik saygısı olumsuz etkilenmekte, yaşam kalitesi düşmekte ve sağlık hizmeti kullanma ihtiyacı artmaktadır (Demir, 2000, s.58; Efe, 2012, s.51; Akpınar, 2013, s.27). Bu nedenle kadınların kadına yönelik eş şiddetinin tedavi edilmesi gereken bir sağlık sorunu olduğunu bilmesi ve bu sorunun üstesinden gelmek için eşi ile birlikte etkin yardım ve danışmanlık alması önemlidir.

\section{AMAÇ}

$\mathrm{Bu}$ çalışma evli kadınların aile içi şiddete maruz kalma durumunu ve etkileyen faktörleri belirlemek amacı ile yapılmıştır.

\section{GEREÇ ve YÖNTEM}

Tanımlayıcı tipteki bu çalışmanın evrenini 1-31 Mayıs 2014 tarihleri arasında, Sivas il merkezinde bir hanımlar kültür merkezinde eğitim alan 330 kadın kursiyer oluşturmuştur. Araştırmada örneklem seçimine gidilmemiş evrenin tamamı örnekleme alınmıştır. Kursiyer kadınlardan 82'si bekar olduğu, 28’i araştırmaya katılmayı kabul etmediği için araştırma kapsamına alınmamıştır. Araştırmanın örneklemini araştırmaya katılmayı kabul eden 18 yaş ve üzeri, evli 220 kadın oluşturmuştur.

Verilerin Kişisel Bilgi Formu ve kadına yönelik aile içi şiddeti belirleme ölçeği ile toplanmıştır.

Kişisel Bilgi Formu: Araştırmacılar tarafından bilimsel literatür doğrultusunda hazırlanmıştır (Devries et al. 2013, s.1528; Garcia-Moreno et al., 2005, s.1283; Günay et al., 2006,s.34; Roman and Frantz, 2013, s.259). Formunda kadının sosyodemografik ve sağlık özelliklerini belirlemeyen 18 soru, eşinin 
sosyodemografik sağlık özelliklerini belirleyen 8 soru ve kadının eşinden şiddet görme durumunu belirlemeye yönelik 2 soru olmak üzere toplam 28 soru yer almaktadır.

Kadına Yönelik Aile İçi Şiddeti Belirleme Ölçeği: Şiddetin sıklığını ve düzeyini belirlemeye yönelik olarak Yanıkkerem ve Saruhan (2005, s.201) tarafindan geliştirilmiş ve geçerlilik güvenilirlik çalışması yapılan ölçek 87 maddeden oluşmaktadır. Ölçekte 5'li Likert tipi sorular ile her kadına şiddete yönelik davranışların hangi sıklıkta ortaya çıktığı sorulmaktadır. Maddeler 1-5 arasında (Hiç: 1, Bir kez ya da nadiren: 2, Bazen: 3, Sıklıkla: 4, Her zaman: 5) puanlandırılmakta olup ölçeğin puan hesabı standartlaştırılmıştır. Buna göre, ölçekten alınan toplam puan en yüksek alınabilecek puana (435) bölünmekte ve 10 ile çarpılmaktadır. Çıkan sonuç 1-10 arasında olmakta ve 0.00-2.00 (çok düşük), 2.014.00 (düşük), 4.01-6.00 (orta), 6.01-8.00 (yüksek) ve 8.01- 10.00 (çok yüksek) olarak değerlendirilmektedir (Yanıkkerem ve Saruhan, 2005, s.202).

Etik yönü ile araştırma Helsinki Deklerasyonu Prensipleri'ne uygun şekilde yürütülmüştür. Araştırma için yazılı kurumsal izin alındıktan sonra, kursiyer kadınlara araştırmanın amacı, yararları açıklanmış, gönüllülük ilkesine dikkat edilerek bilgilendirilmiş onamları alınmıştır. Veri toplama araçları araştırmacılar tarafından kadın kursiyerlere sınıf ortamında ve gözlem altında dağıtılarak veri toplanmıştır. Araştırma verileri SPSS for Windows 14.0 programı kullanılarak analiz edilmiştir. Verilerin değerlendirilmesinde sayı, yüzdelik dağılım, ki-kare testi, $\mathrm{t}$ testi ve varyans analizi uygulanmıştır. Sonuçlar \% 95 güven aralığında, anlamlılık İstatistiksel anlamlılık $\mathrm{p}<0,05$ düzeyinde değerlendirilmiştir. Bu çalışma il merkezinde bulunan hanımlar kültür merkezinde eğitim alan ve araştırmaya katılmayı kabul eden kadınlar ile sınırlıdır.

\section{BULGULAR ve TARTIŞMA}

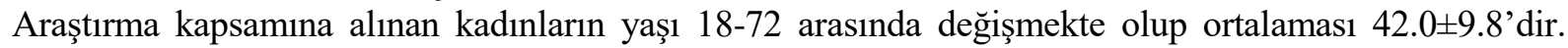
Kadınların kadına yönelik aile içi şiddeti belirleme ölçeği puanı 95-427 arasında değişmekte olup puan ortalamas1 $180.1 \pm 65.5$ 'tir.

Tablo 1. Kadınların ve Eşlerinin Bazı Tanıtıcı Özellikleri

\begin{tabular}{llcc}
\hline Tanımlayıcı Özellikler & & Sayı & \% \\
\hline Yaş & 18-34 yaş arası & 49 & 22.3 \\
& 35-64 yaş arası & 165 & 75.0 \\
& 65 ve üzeri yaş & 6 & 2.7 \\
\hline Eğitim durumu & Okuryazar değil & 6 & 2.7 \\
& Okuryazar & 10 & 4.6 \\
& İlköğretim mezunu & 112 & 50.9 \\
& Lise ve üzeri eğitim & 92 & 41.8 \\
\hline Çalışma durumu & Çalışmıyor (Ev hanımı) & 193 & 87.7 \\
& Çalışıyor & 27 & 12.3 \\
\hline Evlenme şekli & Görücü usulü ile evlenen & 153 & 69.5 \\
& Tanışıp anlaşarak evlenen & 67 & 30.5 \\
\hline Fiziksel hastalık tanısı & Var & 39 & 17.7 \\
& Yok & 181 & 82.3 \\
\hline Ruhsal hastalık tanısı & Var & 22 & 10.0 \\
\hline
\end{tabular}




\begin{tabular}{llll}
\hline & Yok & 198 & 90.0 \\
\hline Eşin yaşı & 18-34 yaş arası & 28 & 12.7 \\
& 35-64 yaş arası & 181 & 82.3 \\
& 65 ve üzeri yaş & 11 & 5.0 \\
\hline \multirow{2}{*}{ Eşin eğitim durumu } & Okuryazar & 3 & 1.4 \\
& İlköğretim mezunu & 75 & 34.1 \\
& Lise ve üzeri eğitim & 142 & 64.5 \\
\hline \multirow{2}{*}{ Eşin çalışma durumu } & Çalışıyor & 191 & 86.8 \\
& Emekli & 26 & 11.8 \\
& Ölmüş & 3 & 1.4 \\
\hline
\end{tabular}

Tablo 1'de kadınların ve eşlerinin bazı tanıtıcı özellikleri görülmektedir. Araştırmada kadınların \%75'i 35-64 yaş grubunda, \%50.9'u ilköğretim eğitimli, \%87.7'si herhangi bir işte çalışmamakta, \%69.5'i görücü usulü ile evlenmiş, \%17.7'si fiziksel hastalık, \%10'u ise ruhsal hastalık tanısına sahiptir. Kadınların eşlerinin \% 82.3'ünün 35-64 yaş grubunda, \%64.5'inin lise ve üzeri eğitimli olduğu, \%86.8'inin aktif olarak bir işte çalıştığı saptanmıştır.

Tablo 2. Kadınların Eşinden Şiddet Görme Durumu, Nedeni ve Düzeyi

\begin{tabular}{llcc}
\hline & & Sayı & Yüzde (\%) \\
\hline Eşinden Görme Durumu & Şiddet gören & 67 & 30.5 \\
& Şiddet görmeyen & 153 & 69.5 \\
\hline Şiddet görme nedeni* & Nedensiz & 33 & 49.3 \\
& Kiskançlık & 14 & 20.9 \\
& Ekonomik koşullar & 25 & 37.3 \\
& Alkol alma & 7 & 10.5 \\
\hline \multirow{2}{*}{ Şiddet görme düzeyi } & Düşük & 131 & 59.5 \\
& Orta & 57 & 25.9 \\
& Yüksek & 28 & 12.7 \\
& Çok yüksek & 4 & 1.8 \\
\hline
\end{tabular}

Tablo 2'de kadınların eşinden şiddet görme durumu, nedeni ve düzeyi görülmektedir. Kadınların \%30.5'i eşinden şiddet gördüğünü ifade etmiş, şiddet gören kadınların \%49.3'ü herhangi bir neden olmaksızın şiddet yaşadığını belirtmiştir. Kadınların tümünün farklı düzeyde şiddet gördüğü ve \%59.5'unun düşük düzeyde şiddet gördüğü saptanmıştır. Yapılan çalışmalarda; Tanrıverdi ve Şıpkın (2008, s.185) kadınların büyük bir çoğunluğunun evliliği boyunca en az bir kez eşi tarafından şiddet gördüğünü, en fazla duygusal şiddetin yaşandığını, Özyurt ve Deveci $(2010$, s.5) kadınların \% 32.9'unun aile içi şiddete maruz kaldığını, bu kadınların \%57.8'ine eşi tarafından çoğunlukla fiziksel şiddet olmak üzere sözel ve cinsel şiddet uygulandığını, Witting et al (2006, s.590) kadınlarda şiddete maruz kalma oranının \% 2 ile \%12 arasında değiştiğini ve bu kadınların gelecekte aile içi şiddete tekrar maruz kalma olasılığının yüksek olduğunu saptamıştır. Araştırma bulgularının bu sonuçlar ile benzerlik gösterdiği ve 
kadına yönelik aile içi şiddetin kadının sağlığı, güvenliğini hatta yaşamını tehdit eden bir sorun olmaya devam ettiği görülmektedir.

Tablo 3. Kadınların Bazı Tanıtıcı Özelliklere Göre Kadına Yönelik Ev İçi Şiddeti Belirleme Ölçeği Puan Ortalamas1

\begin{tabular}{|c|c|c|c|c|}
\hline Tanitıcı Bazı & Özellikler & $\begin{array}{c}\text { Ölçek Puan } \\
\text { Ortalaması X } \pm \text { SD }\end{array}$ & $\mathbf{F}$ & $\mathbf{P}$ \\
\hline \multirow[t]{3}{*}{ Yaş } & 18-34 yaş & $172.2 \pm 64.4$ & 1.043 & 0.354 \\
\hline & 35-64 yaş & $181.3 \pm 65.9$ & & \\
\hline & 65 ve üzeri yaş & $210.8 \pm 63.5$ & & \\
\hline \multirow[t]{4}{*}{ Eğitim durumu } & Okur-yazar değil & $186.0 \pm 70.9$ & 0.793 & 0.499 \\
\hline & Okur-yazar & $162.8 \pm 51.7$ & & \\
\hline & İlköğretim mezunu & $186.0 \pm 65.5$ & & \\
\hline & Lise ve üzeri eğitim & $174.3 \pm 66.7$ & & \\
\hline \multirow[t]{4}{*}{ Eşin eğitim durumu } & Okur-yazar & $202.7 \pm 80.4$ & 0.508 & 0.603 \\
\hline & İlköğretim mezunu & $184.7 \pm 71.1$ & & \\
\hline & Lise ve üzeri eğitim & $177.1 \pm 62.4$ & & \\
\hline & & $\mathbf{t}$ & $\mathbf{p}$ & \\
\hline \multirow[t]{2}{*}{ Evlenme şekli } & Görücü usulü ile evlenen & $166.9 \pm 54.9$ & 2.177 & 0.031 \\
\hline & Tanışıp anlaşarak evlenen & $185.9 \pm 69.1$ & & \\
\hline \multirow[t]{2}{*}{ Çalışma durumu } & Çalışmıyor & $182.5 \pm 64.6$ & 1.369 & 0.180 \\
\hline & Çalışıyor & $162.7 \pm 71.0$ & & \\
\hline \multirow{2}{*}{$\begin{array}{l}\text { Fiziksel } \\
\text { durumu }\end{array}$} & Var & $219.5 \pm 63.0$ & 4.310 & 0.000 \\
\hline & Yok & $171.6 \pm 63.1$ & & \\
\hline \multirow{2}{*}{$\begin{array}{l}\text { Ruhsal } \\
\text { durumu }\end{array}$} & Var & $242.5 \pm 78.5$ & 4.014 & 0.001 \\
\hline & Yok & $173.1 \pm 60.3$ & & \\
\hline \multirow{2}{*}{$\begin{array}{l}\text { Eşinden şiddet görme } \\
\text { durumu }\end{array}$} & Şiddet gören & $243.2 \pm 66.4$ & 12.251 & 0.000 \\
\hline & Şiddet görmeyen & $152.4 \pm 41.8$ & & \\
\hline
\end{tabular}

Tablo 3'te kadınların bazı tanıtıcı özelliklere göre kadına yönelik ev içi şiddeti belirleme ölçeği puan ortalaması görülmektedir. Kadınların evlenme şekli, fiziksel hastalık tanısı, ruhsal hastalık tanısı ve eşinden şiddet görme durumu göre kadına yönelik ev içi şiddeti belirleme ölçeği puan ortalamas1 arasında istatistiksel olarak anlamlı bir fark olduğu saptanmıştır $(\mathrm{p}<0.05)$.

$\mathrm{Bu}$ çalışmada kadınların üçte ikisinin orta yetişkin yaş grubunda olduğu ve \%30.5'inin tanışarak

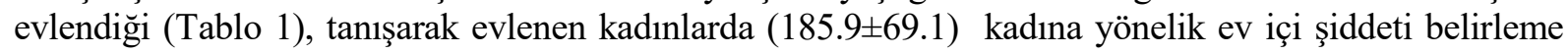
ölçeği puanının görücü usulü evlenen kadınlardan (166.9 \pm 54.9$)$ daha fazla olduğu görülmüştür (Tablo 3). Kadına yönelik şiddetin daha çok genç yetişkin ve orta yetişkin yaştaki kadınlarda görüldüğü 
belirtilmektedir (Miller et al., 2010, s.915). Tanışarak evlenme eşlerin daha iyi anlaşacakları izlenimi vermekle birlikte bu çalışma bulguları kadına yönelik şiddeti önleyemediğini göstermektedir.

Çalışmada fiziksel hastalık tanısı veya ruhsal hastalık tanısı olan ve eşinden şiddet gördügünü ifade eden kadınların kadına yönelik ev içi şiddeti belirleme ölçeği puan ortalamasının daha yüksek olduğu görülmüştür. Kadına yönelik şiddetin kadının fizik ve ruh sağlığını olumsuz etkilediği, şiddet sonucu yaralanma, sakatlanma, cinsel yolla bulaşan hastalıklar, perinatal komplikasyonlar gibi birçok fiziksel sağlık sorunları ile depresyon, anksiyete bozukluğu, psikosomatik hastalıklar, travma sonrası stres bozukluğu gibi ruhsal sorunların görüldüğü belirtilmektedir (Akpınar, 2013, s.27; Efe, 2012, s.52; Ortabağ ve ark., 2014, 671). Yanık ve ark.(2014, s.107) şiddete uğrayan kadınların \%80.9'unda ruh sağlığının bozuk olduğunu saptamıştır. Kadına yönelik ev içi şiddetin kadının fiziksel ve ruhsal bütünlügünü olumsuz etkileyen, sağlık hizmeti ihtiyacını artıran, yalnızca kadını değil aile ve toplumu da etkileyen sonuçları olduğu görülmektedir. Aile içi şiddete maruz kalan kadınların genellikle şiddet yaşantısını gizleme davranışı gösterdiği, sağlık personelinden utanma, şiddet uygulayan kişiden korkma ve kendini suçlu hissetme gibi çeşitli nedenlerle sorunlarını dile getiremediği için şiddet dışında farklı yakınmalarla sağlık kuruluşlarına başvurdukları belirtilmektedir (Coker et al., 2002, s.449; Kothari and Rhodes, 2006, s.197). McCloskey et al. (2005, s.719) farklı yakınmalarla sağlik kuruluşuna başvuran kadınların \%36'sının aile içi şiddete maruz kaldığını saptamıştır. Sağlık çalışanlarının kadın hasta hangi sağl1k sorunu ile gelirse gelsin veri toplarken aile içi şiddeti düşündüren ya da gösteren belirti ve bulguların olmasını beklemeden, kadına şiddete uğrama yaşantısı olup-olmadığını sorması hem şiddeti belirlemede hem de kadının yaşadığı sorunu ifade etmesine firsat vermede büyük önem taşımaktadır.

Çalışmada kadının yaşı, eğitim ve çalışma durumu ile eşin eğitim durumuna göre kadına yönelik ev içi şiddeti belirleme ölçeği puan ortalaması arasında istatistiksel olarak anlamlı bir fark olmadığı saptanmıştır ( $>0.05)$. Konu ile ilgili yapılan çalışmalarda farklı sonuçlar olduğu görülmektedir. Yanık ve ark (2014, s.108) okuma yazma bilmeyen, ev hanımı ve 40 yaş ve üzeri kadınların daha fazla şiddete maruz kaldığını, Efe ve Ayaz (2010, s.28) çalışmaya katılan kadınların tümünün eşinden şiddet gördüğunnü bununla birlikte okur-yazar olmayan, eşi çalışmayan, ekonomik durumu kötü olan ve eşi ile arasındaki yaş farkı fazla olan kadınların daha fazla şiddet gördüğünü, Tanrıverdi ve Şıpkın $(2008$, s.182) ise şiddete en fazla ilkokul mezunu kadınların, en az okur-yazar olmayan kadınlar maruz kaldığını saptamıştır.

\section{SONUÇ ve ÖNERILER}

$\mathrm{Bu}$ çalışmada kadınların ve eşlerinin eğitim durumuna göre ev içi şiddet belirleme ölçeği puan ortalaması arasında istatistiksel olarak anlamlı bir fark olmamakla birlikte eğitim düzeyi düşük olan kadınların ve eşlerinin şiddet ölçeği puan ortalamalarının daha yüksek olduğu görülmüştür. $\mathrm{Bu}$ durum eğitim düzeyinin düşük olmasının bireyin kendini ifade etmesinde ve eşler arası iletişimin sürdürülmesinde önemli bir engel oluşturduğunu ve şiddetin ortaya çıkmasında etkili olduğunu düşündürmektedir. Eğitim, kişinin kendini ifade etme becerisini geliştirmesine ve kişisel farklındalığının artmasına katkı verdiğinden eğitim seviyesinin düşmesi bireyin problem çözmede yetersiz olmasına ve başetme sorunları yaşamasına neden olabilmektedir.

Çalışmaya katılan kadınların eş şiddetini doğrudan ifade edemedikleri, sadece üçte birinin şiddet gördüğünü belirttiği, okur yazar olmayan kadınların sayısının çok az olmakla birlikte şiddet puan ortalamasının çok yüksek olduğu görülmüştür. Bu sonuçta şiddetin toplumda evlilik ilişkisinin olağan bir parçası olarak algılanması, gizli tutulup paylaşılmaması gerektiği gibi mitlerin etkili olduğu düşünülmektedir. Kadına yönelik ev içi şiddetin ele alınmasında ve şiddetteki kısır döngünün kırılmasında şiddete uğrayan kadın kadar şiddeti uygulayan eşin de değerlendirilmesi, yardım ve destek gereksinimlerinin belirlenmesi büyük önem taşımaktadır. Bu nedenle şiddete yaklaşımda şiddeti ortaya çıkaran durumun tanımlanması kadın ve erkeğin duygu ve davranışlarını tanıması ve gerçekçi olarak değerlendirebilecek bir farkındalığa ulaşması yönünde desteklenmesi önerilmektedir.

Sonuç olarak, mevcut çalışmanın Sivas ili ile ve 18 yaş üzeri evli kadınlarla sınırlı olduğu dikkate alındığında benzer çalışmaların ülkemizin farklı coğrafi ve sosyoekonomik özellikteki illerinde yapılması, genç, yetişkin ve yaşlı olmak üzere farklı gelişim dönemlerindeki kadınlarda ele alınmasının kadına yönelik eş şiddetinin genel bir tablosunun çıkarılması hususunda gereklilik arz ettiği 
düşünülmektedir. Ayrıca mevcut çalışma sonuçları doğrultusunda; kadınların aile içi eş şiddeti türleri ve aile içi eş şiddetinin tedavi edilmesi gereken bir sorun olduğu konusunda bilgilendirilmesi, şiddet yaşantısında yardım ve destek alacakları kaynaklarının tanıtılması, şiddetin sonuçlarına yönelik farkındalıklarının artırılması önerilmektedir.

Bilgilendirme / Acknowledgement: Çalışmanın sağlıkı uygulanmasına katkıda bulundukları için Hanımlar Kültür Merkezi yönetimi ve çalışanlarına ve çalışmaya katılmayı kabul eden kadınlara teşekkür ederiz. Çalışmanın yürütülmesi ve makalenin yazımı süresince finansal bir destek alınmamıştır. Yazarlar arasında bir çıkar çatışması yoktur.

$\mathrm{Bu}$ çalışma, 2014 yılında üniversitenin 40. yıl etkinlikleri kapsamında ili merkezinde 40 kurumda gerçekleştirilen eğitimler kapsamında planlanmıştır. Ayrıca 17-20 Haziran 2015 tarihleri arasında İzmir'de düzenlenen 1. Ulusal Halk Sağlığı Hemşireliği Kongresi’nde sözel bildiri olarak sunulmuştur.

\section{KAYNAKÇA}

Akpınar, O. (2013). Aile içi şiddete maruz kalan kadınlarda aile içi şiddetle başa çıkma özyeterliği. Türk Psikolojik Danışma ve Rehberlik Dergisi, 4(39), 24-36.

Altınay, A.G. ve Arat, Y. (2007). Türkiye'de Kadına Yönelik Şiddet. İstanbul, Punto Baskı Çözümleri.

Ayrancı, Ü., Günay Y. ve Ünlüoğlu İ. (2002). Hamilelikte aile içi eş şiddeti: birinci basamak sağlk kurumuna başvuran kadınlar arasında bir araştırma. Anadolu Psikiyatri Dergisi, 2(3), 75-87.

Coker, A.L., Bethea, L., Fadden, M.K., King, M.R. and Smith, P.H. (2002). Missed opportunities: Intimate Partner Violence (IPV) in family practice settings. Preventive Medicine, 34(4) 445-454. doi:10.1006/pmed.2001.1005.

Demir, Ü. (2000). Kadına yönelik aile içi şiddet. Atatürk Üniv. Hemşirelik Yüksekokulu Dergisi, 3(1), 57-61.

Efe, Ş.Y. ve Ayaz, S. (2010). Kadına yönelik aile içi şiddet ve kadınların aile içi şiddete bakışı. Anadolu Psikiyatri Dergisi, 11(1), 23-29.

Efe, Ş.Y.(2012). Acil servis hemşirelerinin kadına yönelik aile içi şiddete ilişkin rol ve sorumlulukları. F.Ü. Să̆. Bil. Tip Derg., 26(1), 49-54.

Devries, K.M., Mak, J.Y.T., García-Moreno. C., Petzold. M., Child, J.C., Falder, G, Lim, S., Bacchus, L.J., Engell, R.E., Rosenfeld, L., Pallitto, C., Vos, T., Abrahams, N. and Watts, C.H. (2013). The global prevalence of intimate partner violence against women. Science, 340(6140), 1527-1528.

Garcia-Moreno, C., Heise, L., Jansen, HAFM., Ellsberg, M. and Watts, C. (2005). Violence against women. Science, 310(5752), 1282-1283.

Günay, T., Giray, H., Harç, B., Köksal, B. ve Sarı, S. (2006). İzmir'de bir gecekondu bölgesinde kadına yönelik aile içi şiddet. Sağlık ve Toplum, 16(3), 31-7.

Kaplan, S., Akalın, A., Pınar, G. ve Yılmazer, T. (2014). Hemşirelik öğrencilerinin kadına yönelik aile içi şiddet ve aile içi şiddette mesleki rollerine ilişkin tutumları. Yıldırım Beyazıt Sağlık Bilimleri Fakültesi Hemşirelik e-Dergisi, 2(1) 26-35.

Kothari, C.L. ve Rhodes, K.V. (2006). Missed opportunities: emergency department visits by policeidentified victims of intimate partner violence. Ann Emerg Med, 47(2), 190-199.

McCloskey, L.A., Lichter, E., Ganz, M.L., Williams, C.M., Gerber, M.R., Sege, R., Stair, T. and Herbert, B. (2005). Intimate partner violence and patient screening across medical specialties. Acad Emerg Med, 12(8), 712-722.

Miller, E., Decker, M.R., Raj, A., Reed, E., Marable, D. and Silverman, J.G. (2010). İntimate partner violence and health care-seeking patterns among female users of urban adolescent clinics. Matern Child Health J, 14(6), 910-917. 
Ortabağ, T., Özdemir, S., Bebiş, H. ve Ceylan, S. (2014). Perspectives of young adultmen regarding violence against women: a cross-sectional study from Turkey. J Fam Viol, 29(6), 665-674.

Özyurt, S.C. ve Deveci, A. (2010). Manisa'da kırsal bir bölgedeki 15-49 yaş evli kadınlarda depresif belirti yaygınlığı ve aile içi şiddetle ilişkisi. Türk Psikiyatri Dergisi, 21(1), 1-7.

Roman, N.V. and Frantz, J.M. (2013).The prevalence of intimate partner violence in the family: a systematic review of the implications for adolescents in Africa. Fam Pract, 30(3), 256-265.

Selvi, Ü.Y. ve Karanfil, D. (2016). Intimate partner violence against women: Effects of power distance, individualism and economy. Journal of Human Sciences, 13(1), 60-72.

Stöckl, H., Devries, K., Rotstein, A., Abrahams, N., Campbell, J., Watts, C. and Moreno, C.G. (2013). The global prevalence of intimate partner homicide: a systematic review. Lancet, 382(9895), 859-865.

Tanrıverdi, G. ve Şıpkın, S. (2008). Çanakkale'de sağlık ocaklarına başvuran kadınların eğitim durumunun şiddet görme düzeyine etkisi. Firat Tıp Dergisi, 13(3), 183-187.

Tatl11ıoğlu, K. ve Küçükköse, İ. (2015). Türkiye'de kadına yönelik şiddet: nedenleri, koruma, önleme ve müdahale hizmetleri. Dicle Üniversitesi Sosyal Bilimler Enstitüsü Dergisi, 7(13), 194-209.

T.C. Aile ve Sosyal Politikalar Bakanlığı Kadının Statüsü Genel Müdürlüğü (2015). Türkiye'de kadına yönelik aile içi şiddet araştırması (2015). Ankara: Elma Teknik Basım Matbaası. T.C. Aile ve Sosyal Politikalar Bakanlığı Kadının Statüsü Genel Müdürlüğü Yayınları,

Witting, M.D., Furuno, J.P., Hirshon, J.M., Krugman, S.C. and Périssé, ARS. (2006). Support for emergency department screening for intimate partner violence depends on perceived risk. $J$ Interpers Violence, 21(5), 585-596.

World Health Organization (2002). World report on violence and health. 27 Mays 2018 tarihinde http://whqlibdoc.who.int/publications/2002/9241545615_eng.pdf adresinden erişildi.

World Health Organization (2005). Multi-country study on women's health and domestic violence against women: summary report of initial results on prevelance, health outcomes and women's response. Geneva. 17 Mart 2018 tarihinde http://www.int/iris/bit stream/10665/1/978941564625_eng.pdf. adresinden erişildi.

World Health Organization (2013). Global and regional estimates of violence against women: prevalence and health effects of intimate partner violence and non-partner sexual violence. 17 Mart 2018 tarihinde http://www.int/iris/bitstream/10665/1/978 941564625_eng.pdf adresinden erișildi.

Yanık, A., Hanbaba, Z., Soygör, S., Ayaltı, B. ve Doğan, M. (2014). Kadına yönelik şiddet davranışlarının değerlendirilmesi: Türkiye'den kanıt. Electronic Journal of Vocational Colleges, 4(4), 105-111.

Yanıkkerem, E. ve Saruhan, A. (2005). 15-49 yaş evli kadınların aile içi şiddet konusunda görüşlerinin ve aile içi şiddete maruz kalma durumlarının incelenmesi. MN Klinik Bilimler \& Doktor, (11), 198-204. 